\begin{tabular}{|c|c|c|}
\hline$W_{\text {INESEG }}$ & $\begin{array}{l}\text { INTERNATIONAL } \\
\text { ENGINEERING, } \\
\text { SCIENCE AND } \\
\text { EDUCATION } \\
\text { GROUP }\end{array}$ & $\begin{array}{l}\text { Middle East Journal of Science } \\
\text { (2017) 3(1): } 1-8 \\
\text { Published online August } 28,2017 \quad \text { (http://dergipark.gov.tr/mejs) } \\
\text { doi: } 10.23884 / \text { mejs.2017.3.1.01 } \\
\text { ISSN: } 2536-5312\end{array}$ \\
\hline
\end{tabular}

\title{
DETERMINATION OF SOME BIOLOGICAL PARAMETERS HENOSEPILACHNA ELATERII ROSSI (COLEOPTERA: COCCINELLIDAE) ON DIFFERENT WATERMELON CULTIVARS
}

\section{Erol Bayhan ${ }^{1}$, Selime ÖLMEZ BAYHAN ${ }^{* 2}$}

${ }^{1}$ Dicle University, Agricultural Faculty, Department of Plant Protection, Diyarbakır, Turkey

${ }^{* 2}$ Dicle University, Agricultural Faculty, Department of Plant Protection, Diyarbakır, Turkey

$$
\text { *solmez@dicle.edu.tr }
$$

Phytophagus coccinellid belong to Epilacchninae sub-family are very different the other coccinellid, and found in tropical and subtropical regions of the world. Henosepilachna elaterii Rossi. feeds on plants of Cucurbitacae family in groups in Europe, Africa and Asia. This pest is found the south Europe, Mediterranean regions, and south of Center Europe. Henosepilachna elaterii is a serious pest of watermelon and cantaloupe, and is a common pest in Aegean region and Southeastern Anatolia Region of Turkey. This species is a vector as different virus disease from health plant to disease plant. This study was carried out to determine biological parameters of Henosepilachna elaterii Rossi. (Coleoptera: Coccinellidae) feeded on watermelon cultivars (Sürme, Galactica, Crimson sweet, Crimson tide and Sugar baby). The trials were made in laboratory conditioned at 16:8 h (day:night) and in $65 \pm 5 \%$ relative humidity at $25 \pm 1{ }^{\circ} \mathrm{C}$ temperature. Data was collected on effect of host plants cultivars on preadult periods. Total development time at prematuring period was shortest at $25 \pm 1{ }^{\circ} \mathrm{C}$ on Crimson tide cultivar as 24.41 days and longest as 25.01 days on Sürme cultivars.

Key words: Henosepilachna elaterii, Developmental time, Cultivars of watermelon 


\title{
HENOSEPILACHNA ELATERII ROSSI (COLEOPTERA: COCCINELLIDAE)'NIN FARKLI KARPUZ ÇEŞITLERINDE BAZI BIYOLOJIK PARAMETRELERININ BELIRLENMESI
}

\begin{abstract}
Epilachninae alt familyasindaki fitofag gelinböcekleri çok farklı olup, dünyanin tropik ve subtropik bölgelerinde bulunmaktadır. Henosepilachna elaterii Rossi türünün Avrupa, Afrika ve Asya'nın güney ve batısinda Cucurbitaceae familyası bitkilere gruplar halinde saldırdı ğ bildirilmektedir. Güney Avrupa Akdeniz Bölgesi, Kuzey Afrika ve Güney Sibirya'da bulunduğunu ve Akdeniz Bölgesi'nin tipik bir türü olup, Orta Avrupa'nın güneyine kadar yayıldı̆̆ını bildirmektedir. Ülkemizde de yaygın olduğu, özellikle Ege ve Güneydoğu Anadolu Bölgesi’nde önemli bir kavun-karpuz zararlısı olduğu bildirilerek, özellikle kabak mozaik virüsünün doğadaki konukçusu yabani hıyardan kültür bitkilerine yayılmasinda önemli bir vektör olduğu kaydedilmiştir.Bu çalışma ile H. elaterii Rossi (Coleoptera: Coccinellidae)'nin ergin öncesi gelişim dönemlerine ait bazı biyolojik parametreleri karpuz çeşitleri üzerinde (Sürme, Galactica, Crimson sweet, Crimson tide and Sugar baby) belirlenmiştir. Çalışma kontrollü koşullarda (16:8 aydınlatmalı, \% $65 \pm 5$ orantılı nem, $25 \pm 1{ }^{\circ} \mathrm{C}$ sicaklık) yürütülmüştür. Zararlı ergin öncesi gelişme süresini en klsa Crimson tide çeşidi üzerinde 24.41 gün, en uzun gelişimi ise Sürme çeşidi üzerinde 25.01 gün olarak tamamlamıştır.
\end{abstract}

Anahtar Kelimeler: Henosepilachna elaterii, Gelişme süresi, Karpuz çeşitleri

\section{Giriş}

Güneydoğu Anadolu Bölgesi'nde sebze tarımı yapılan illerin başında Diyarbakır ili gelmektedir. Diyarbakır'da yıllardan beri yetiştirilen, yöreyle özdeşleşmiş, tat ve lezzet açısından yöre insanının tüketim alışkanlığına uygun olan karpuz önemli tarımsal ürünler arasında yer almaktadır. Diyarbakır ili karpuz ekimi, alan ve üretim miktarı açısından bölge ve ülke üretiminde önemli bir yer tutmaktadır.

Coccinellidae familyasındaki türlerin büyük bir çoğunluğu kültür bitkileri için zararlı birçok böcek ve kırmızı örümcek gibi türleri avlayarak beslendiği için faydalı böcekler olarak bilinmektedir. Bitki zararlısı (fitofag) türler azdır ve bunlardan en önemlilerini Henosepilachna cinsine bağlı türler oluşturmaktadır[1]. Bu türler karpuz, kavun, kabak ve hıyar gibi Cucurbitaceae familyası bitkilerinde beslenmektedir [2,3].

Epilachninae alt familyasındaki fitofag gelinböcekleri, dünyanın tropik ve subtropik bölgelerinde bulunmaktadır[4,5]. H. elaterii türünün Avrupa, Afrika ve Asya'nın güney ve batısında Cucurbitaceae familyası bitkilere gruplar halinde zarar bildirilmektedir[6,7]. Ayrıca araştırıcılar, zararlının Güney 
Avrupa Akdeniz Bölgesi, Kuzey Afrika ve Güney Sibirya' da bulunduğunu ve Akdeniz Bölgesi’nin tipik bir türü olup, Orta Avrupa'nın güneyine kadar yayıldığını bildirmektedir[8,9].

Karpuz telliböceği, Ege ve Güneydoğu Anadolu Bölgesi'nde önemli bir kavun ve karpuz zararlıs1 olduğu bildirilerek, özellikle kabak mozaik virüsünün doğadaki konukçusu yabani hıyardan kültür bitkilerine yayılmasında önemli bir vektör olduğu kaydedilmiştir $[10,11]$.

Henosepilachna elaterii polifag bir zararlı olup, karpuz üretiminde önemli zararlara neden olmaktadır. Diğer zararlılarda olduğu gibi bu zararlıya karşı da başarılı bir mücadele yapılabilmesi için zararlının biyolojisi ve ekolojisinin araştırılması gerekmektedir. Bu nedenle ele alınan çalışmada, bölgemizde karpuzun önemli bir zararlısı olan Zararlının laboratuvar koşullarında farklı karpuz çeşitlerindeki bazı biyolojik parametreleri ortaya çıkarılmıştır.

$\mathrm{Bu}$ çalışmada; Diyarbakır ilinde ekilişleri yapılan farklı karpuz çeşitleri üzerinde Karpuz telliböceğinin laboratuvar koşullarında bazı biyolojik parametreleri ortaya çıkarılmıştır.

\section{Yöntem}

\subsection{Bitki Üretim Çalışmaları}

Denemelerde kullanılan Karpuz telliböceğini üretmek için çalışma boyunca karpuz üretimi çalışmada ele alınan karpuz çeşitleri (Sürme, Crimson sweet, Crimson tite, Sugar Baby ve Galactica) iklim odalarında yetiştirilmiştir.

\subsection{Böcek Üretim Çalışmaları}

Diyarbakır'da karpuz üretimi yapılan arazilerde Cucurbitaceae türleri üzerinde bulunan H. elaterii ile bulaşık bitki yaprakları kopartılıp kâğıt torbalara konularak laboratuvara getirilmiştir. Zararlı üretiminin devamlılığını sağlamak amacıyla bitki üretim odasından gerek duyulduğunda böcek üretimi odasındaki tül kafeslere yeni bitkiler yerleştirilmiştir.Karpuz telliböceği üretimi, çalışma boyunca farklı karpuz çeşitleri üzerinde kafesler içerisinde yapılmıştır.

Denemede kullanılan konukçu bitki ve böcek üretimi $25 \pm 1$ 0C sıcaklık ile $\% 65 \pm 5^{\prime}$ lik orantılı neme ayarlı uzun gün aydınlatmalı $(16: 8)$ bitki üretim odalarında gerçekleştirilmiştir.

\subsection{Henosepilachna elaterii’nnin Farklı Karpuz Çeşitleri Üzerindeki Biyolojisi}

Henosepilachna elaterii'nin farklı karpuz çeşitleri üzerindeki biyolojileri $25 \pm 10 \mathrm{C}$ sabit sıcaklık değerinde iklim dolabında \% $65 \pm 5$ orantılı nemde, uzun gün aydınlatmalı (16:8) koşullarda yürütülmüştür. Farklı karpuz çeşitleri üzerinde yürütülecek olan çalışmada H. elateri'nin F1 bireyleri denemeye alınmıştır. Denemeye alınan bir günlük nimfler $9 \mathrm{~cm}$ çap ve $1.5 \mathrm{~cm}$ yüksekliğindeki her bir petri kutusu içerisinde bir adet larva olacak şekilde, sıfır numaralı samur firça yardımıyla çapına göre kesilmiş karpuz yaprağı diskleri üzerine bırakılmıştır. Her bir çeşit için deneme 20 yinelemeli olarak yürütülmüş ve $3 \mathrm{kez}$ tekrarlanmıştır. Denemeye alınan bir günlük larvaların bulunduğu petriler günde bir kez aynı saatlerde olmak koşuluyla kontrol edilmiş ve deri değiştiren bireylerin derileri ortamdan 
uzaklaştırılarak dönemleri kaydedilmiştir. Bu bireyler ergin oluncaya kadar izlenmiş ve karpuz çeşitleri üzerinde H. elaterii'nin ergin öncesi gelişme süreleri saptanmıştır.

\section{Bulgular}

Yumurta dönemi 4.2 gün ile sürme çeşidinde en kısa, 4.26 gün ile Crimson sweet çeşidinde en uzun olarak bulunmuştur. Karpuz çeşitlerine göre yumurta dönemi açılım süresi arasındaki fark istatiski olarak önemsiz bulunmuştur (Tablo 1). Giray (1971), $26{ }^{\circ} \mathrm{C}$ de yumurta açılım süresini konukçu bitki belirtmeksizin 4-5 gün, ortalama gelişim süresini 4.34 gün sürdüğünü bildirmiştir. Ayrıca yumurta açılım süresini Ghabn (1951) $24{ }^{\circ} \mathrm{C}$ süreyi 3-7 gün ortalama 3.81 gün, Melamed (1956) ise $27-30{ }^{\circ} \mathrm{C}$ de 3-6 gün olarak belirtmiştir.

Birinci larva dönemini Sürme, Galactica, Crimson sweet, Crimson tide ve Sugar baby karpuz çeşitlerinde sırasıyla 3.68, 4.05, 3.98, 4.05 ve 4.05 gün olarak tespit edilmiştir (Tablo 1). Konukçu bitkilere göre birinci larva dönemi süresi arasındaki fark istatistiki olarak önemli bulunmuştur $(\mathrm{P}<0.05)$. Giray (1971), 26 ${ }^{\circ} \mathrm{C}$ de birinci larva dönemini konukçu bitki belirtmeksizin 4-5 gün, ortalama gelişim süresini 4.35 gün sürdüğünü bildirmiştir. çeşidi belirtmemiş karpuz üzerinde birinci larva gelişim süresini 3.08 gün olarak belirtmiştir[12].

İkinci larva dönemi süresi karpuz çeşitlerine göre 2.90 gün ile en kısa Galactica'da, 3.00 gün ile en uzun Crimson tide üzerinde tamamladığı belirlenmiş̧ir. Karpuz çeşitleri üzerinde gelişen bireyler 2. larva dönemi süreleri aralarındaki fark istatistiki olarak önemsiz, bulunmuştur (Tablo 1). Perret (1938)'e göre $26.9^{\circ} \mathrm{C}$ 'de 3-6 gün, ise bu süre konukçu belirtmeksizin $26^{\circ} \mathrm{C}$ 'de ortalama 3.11 gün ve Sağlam (2003) ise bu dönemi 3.17 gün olarak bildirmiştir[13].

Karpuz telliböceğin üçüncü larva dönemi 2.98 gün ile Crimson tide çeşidinde en kısa, 3.11 gün ile Sürme çeşidinde en uzun olarak saptanmıştır (Tablo 1). Karpuz çeşitleri üzerinde 3. larvaların gelişim süreleri arasındaki fark istatistiki olarak önemsiz bulunmuştur $(\mathrm{P}<0,05)$.konukçu belirtmeksizin ele alınan zararlının üçüncü larva dönemini, $26^{\circ} \mathrm{C}$ 'de ortalama 3.07 gün, $25^{\circ} \mathrm{C}$ ortalama 4.56 gün sürdüğünü kaydetmiştir. Zararlıya ait aynı dönemin gelişme süresini Sağlam (2003) çeşidi belirtilmeyen karpuz bitkisinde 3.73 gün olarak belirtmiştir[14].

Zararlının 4. larva dönemini tamamlama süresi 3.51 gün ile Crimson tide en kısa, 4.08 gün ile Sürme'de en uzun saptanmıştır. Galactica, Crimson sweet, Crimson tide ve Sugar baby çeşitlerinde yetiştirilen bireyler arasında, 4. larva dönemini tamamlama süreleri arasındaki fark istatistiki olarak önemsizken, Sürme çeşidindeki fark istatistiki olarak önemli bulunmuştur (Tablo 1). Bu son larva dönemi 20 C'de 46 gün ve ortalama 4.40 günde tamamladığını belirtmektedir[15]. Bu gelişme süresini $26^{\circ} \mathrm{C}^{\prime}$ de ortalama 3.42 gün olarak bildirmiştir. Bulunan sonuçlarla benzerlik görülmektedir. Karpuzda bu süreyi 4.11 gün olarak bildirmiştir[16].

Zararlıya ait Prepupa dönemleri incelendiğinde 1.53 gün ile Sürme'de en kısa, 1.80 gün ile Sugar baby'de en uzun olduğu ve çalışmada ele alınan bütün karpuz çeşitleri arasındaki farkın istatistiki olarak önemsiz olduğu bulunmuştur (Tablo 1). Prepupa dönemi hakkında çok kısa bilgiler vermiş ve bu dönemi sicaklık derecesi belirtmeden 2-3 gün kadar sürdüğünü belirtmiştir[17]. Konukçu belirtmeksizin zararlının prepupa dönemini, $26{ }^{\circ} \mathrm{C}^{\prime}$ de ortalama 1.52 günde tamamladığını bildirmektedir[18]. $\mathrm{Bu}$ dönemi çeşidi belirtilmeyen karpuzda 2.13 günde tamamladığını bildirmiştir[19].

Pupa dönemi 4.86 gün ile Sugar baby'de en kısa, 5.38 gün ile Sürme'de en uzun sürede tamamladığı saptanmıştır. Galactica, Crimson sweet, Crimson tide ve Sugar baby çeşitleri üzerinde gelişen bireylerin 
pupa süreleri aralarındaki farkın istatistiki olarak önemsiz olduğu, Sürme üzerinde gelişen bireyler ile diğer çeşitler arasındaki fark ise istatistiki olarak önemli bulunmuştur (Tablo 1). Pupa süresini 4.11 gün, $26^{\circ} \mathrm{C}$ ' de bu süreyi sırasıyla ortalama $4.40,7.00$ ve 5.50 gün olarak bildirmektedirler[20-23]. Pupa süresini çeşidi belirtilmeyen karpuzda 5.68 günde tamamladığını bildirmiştir[24].

Toplam gelişme süresi açısından karşılaştırıldığında, H.elaterii’nin gelişimini 24.41 gün ile Crimson tide'da en kısa, 25.01 gün ile Sürme'de en uzun sürede tamamladığı tespit edilmiştir (Tablo 1). Crimson sweet ve Crimson tide karpuz çeşitleri ergin öncesi toplam gelişme süresi açısından aralarındaki fark istatistiki olarak önemsiz bulunmuştur. Zararlının ergin öncesi gelişme süresini çeşidi belirtilmemiş karpuz bitkisinde 21.52 günde tamamladığını belirtmiştir. Çalışmamızda elde edilen veriler ile bu çalışma benzerlik göstermektedir[ $[25,26]$.

Çalışmada ele alınan karpuz çeşitlerine göre ergin öncesi gelişme dönemlerinde meydana gelen ölüm oranları Tablo 2.'de verilmektedir. Tablo incelendiğinde yumurta, I, II, III ve IV. larva ve prepupa döneminde ölüm meydana geldiği görülmektedir. Pupa dönemlerinde ölümlerin meydana gelmediği saptanmıştır. Toplam ölüm oranlarına bakıldığında, ölüm oranının en fazla Sürme'de, en az ise Galactica çeşidinde meydana geldiği görülmektedir (Tablo 2).

Tablo 1. Henosepilachna elaterii'nin $25 \pm 1^{\circ} \mathrm{C}$ sıcaklıkta farklı karpuz çeşitleri üzerindeki ergin öncesi dönemlere ait gelişim süreleri (Gün)

\begin{tabular}{|c|c|c|c|c|c|c|c|c|}
\hline $\begin{array}{r}\text { Kon } \\
\text { ukçu Bitki }\end{array}$ & Yum & $\begin{array}{ll} & 1 . \\
\text { Larva } & \\
& \text { (g } \\
\text { ün) } & \end{array}$ & $\begin{array}{l}\begin{array}{l}2 . \\
\text { Larva } \\
\text { ün) }\end{array} \\
\text { (g }\end{array}$ & $\begin{array}{l}\text { Larva } \\
\text { (g } \\
\text { ün) }\end{array}$ & $\begin{array}{l}\begin{array}{l}4 . \\
\text { Larva } \\
\text { ün) }\end{array} \\
\text { (g }\end{array}$ & $\begin{array}{l}\text { Pr } \\
\text { epupa } \\
\text { ün) } \\
\end{array}$ & $\begin{array}{l}{ }_{\text {upa }} \\
\\
\text { ün) } \\
\end{array}$ & $\begin{array}{l}\text { Top } \\
\text { lam } \\
\text { Gelişme } \\
\text { (gün) }\end{array}$ \\
\hline Sür & $\begin{array}{r}4,20 \pm \\
0,05 a^{*} \\
\end{array}$ & $\begin{array}{r}3,68 \\
\pm 0,06 \mathrm{a} \\
\end{array}$ & $\begin{array}{r}2,96 \pm \\
0,07 \mathrm{a} \\
\end{array}$ & $\begin{array}{r}3,11 \\
\pm 0,06 \mathrm{a} \\
\end{array}$ & $\begin{array}{r}4,08 \pm \\
0,06 \mathrm{~b} \\
\end{array}$ & $\begin{array}{r}1,53 \pm \\
0,07 \mathrm{a} \\
\end{array}$ & $\begin{array}{r}5,38 \\
\pm 0,06 \mathrm{~b} \\
\end{array}$ & $\begin{array}{r}25,01 \\
\pm 0,18 \mathrm{~b} \\
\end{array}$ \\
\hline Gala & $\begin{array}{r}4,23 \pm \\
0,04 \mathrm{a}\end{array}$ & $\begin{array}{r}4,05 \\
\pm 0,02 \mathrm{~b} \\
\end{array}$ & $\begin{array}{r}2,90 \pm \\
0,07 \mathrm{a}\end{array}$ & $\begin{array}{r}3,05 \\
\pm 0,06 \mathrm{a} \\
\end{array}$ & $\begin{array}{r}3,61 \pm \\
0,06 \mathrm{a}\end{array}$ & $\begin{array}{l}1,71 \pm \\
0,06 \mathrm{a}\end{array}$ & $\begin{array}{r}4,96 \\
\pm 0,09 \mathrm{a} \\
\end{array}$ & $\begin{array}{r}24,53 \\
\pm 0,17 \mathrm{ab}\end{array}$ \\
\hline $\begin{array}{l}\text { Crim } \\
\text { son Sweet }\end{array}$ & $\begin{array}{r}4,26 \pm \\
0,03 \mathrm{a}\end{array}$ & $\begin{array}{r}3,98 \\
\pm 0,03 \mathrm{~b}\end{array}$ & $\begin{array}{l}2,96 \pm \\
0,06 \mathrm{a}\end{array}$ & $\begin{array}{r}3,00 \\
\pm 0,06 \mathrm{a}\end{array}$ & $\begin{aligned} 3,56 \pm \\
0,05 \mathrm{a}\end{aligned}$ & $\begin{array}{l}1,61 \pm \\
0,07 \mathrm{a}\end{array}$ & $\begin{array}{r}5,06 \\
\pm 0,11 \mathrm{a}\end{array}$ & $\begin{array}{r}24,46 \\
\pm 0,18 \mathrm{a}\end{array}$ \\
\hline $\begin{array}{l}\text { Crim } \\
\text { son Tide }\end{array}$ & $\begin{array}{l}4,25 \pm \\
0,03 \mathrm{a}\end{array}$ & $\begin{array}{r}4,05 \\
\pm 0,04 \mathrm{~b} \\
\end{array}$ & $\begin{array}{r}3,00 \pm \\
0,07 \mathrm{a} \\
\end{array}$ & $\begin{array}{r}2,98 \\
\pm 0,07 \mathrm{a}\end{array}$ & $\begin{array}{l}3,51 \pm \\
0,06 \mathrm{a}\end{array}$ & $\begin{array}{l}1,62 \pm \\
0,07 \mathrm{a}\end{array}$ & $\begin{array}{r}5,00 \\
\pm 0,11 \mathrm{a}\end{array}$ & $\begin{array}{r}24,41 \\
\pm 0,19 \mathrm{a}\end{array}$ \\
\hline $\begin{array}{l}\text { Suga } \\
\text { r Baby }\end{array}$ & $\begin{array}{r}4,23 \pm \\
0,05 \mathrm{a}\end{array}$ & $\begin{array}{r}4,05 \\
\pm 0,02 \mathrm{~b}\end{array}$ & $\begin{array}{r}2,96 \pm \\
0,06 \mathrm{a}\end{array}$ & $\begin{array}{r}3,01 \\
\pm 0,07 \mathrm{a}\end{array}$ & $\begin{array}{r}3,65 \pm \\
0,05 \mathrm{a}\end{array}$ & $\begin{array}{r}1,80 \pm \\
0,05 \mathrm{a}\end{array}$ & $\begin{array}{r}4,86 \\
\pm 0,07 \mathrm{a}\end{array}$ & $\begin{array}{r}24,56 \\
\pm 0,16 \mathrm{ab}\end{array}$ \\
\hline
\end{tabular}

*Aynı sütunda farklı harfler istatistiki olarak farklı grupları oluşturmaktadır $(\mathrm{P}<0,05)$ 
Tablo 2. Henosepilachna elaterii' nin $25 \pm 1^{\circ} \mathrm{C}$ sıcaklıkta farklı karpuz çeşitleri üzerindeki ergin öncesi dönemlerinin ölüm oranları (\%)

\begin{tabular}{|c|c|c|c|c|c|c|c|c|c|}
\hline $\begin{array}{l}\text { Konu } \\
\text { kçu Bitki }\end{array}$ & o* & umurta & Larva & $\begin{array}{r}2 . \\
\text { Larva }\end{array}$ & $\begin{array}{r}3 \\
. L a r v a\end{array}$ & $\begin{array}{r}4 \\
. L a r v a\end{array}$ & $\begin{array}{r}\text { Pr } \\
\text { epupa }\end{array}$ & upa & $\begin{array}{l}\text { Toplam } \\
\text { Gelişme } \\
\text { Dönemi }\end{array}$ \\
\hline Sürme & 00 & 6 & 8.5 & 13.95 & $\begin{array}{r}9 . \\
45\end{array}$ & 7.46 & 3.22 & 0 & 48.58 \\
\hline $\begin{array}{l}\text { Galacti } \\
\text { ca }\end{array}$ & 0 & 55 & $\begin{array}{r}14.8 \\
6 \\
\end{array}$ & 5.40 & $\begin{array}{r}8 . \\
57\end{array}$ & 0 & 0 & 0 & 32.46 \\
\hline $\begin{array}{l}\text { Crims } \\
\text { on Sweet }\end{array}$ & 0 & $\begin{array}{r}4 . \\
44 \\
\end{array}$ & $\begin{array}{rr} & 16.2 \\
7 & \\
\end{array}$ & 9.72 & 56 & 1.53 & 1.58 & 0 & 35.10 \\
\hline $\begin{array}{l}\text { Crims } \\
\text { on Tide }\end{array}$ & 0 & 22. & 7.95 & 6.17 & $.84^{11}$ & 4.47 & 1.56 & 0 & 34.21 \\
\hline $\begin{array}{ll} & \text { Sugar } \\
\text { Baby } & \\
\end{array}$ & 0 & $\begin{array}{r}6 . \\
66 \\
\end{array}$ & 4.76 & 8.75 & .32 & 6.06 & 0 & 0 & 38.55 \\
\hline
\end{tabular}

$\mathrm{N}_{0}{ }^{*}$ Başlangıçtaki Yumurta Sayısı

\section{Sonuçlar}

Karpuz telliböceğinin biyolojik parametrelerine yönelik yapılan çalışmalar oldukça sınırlı olduğu için bu araştırmada elde edilen sonuçların bu konuda yapılacak olan çalışmalara yararlı olacağı düşünülmektedir.

\section{Teşekkür}

Bu araştırmaya maddi destek veren Dicle Üniversitesi Araştırma Projeleri Birimi (DÜBAP Proje No: 08ZF57)'ne teşekkürlerimizi sunarız. 


\section{Kaynakça}

[1] Al Iraqi, R.A., Farag, F.A., \& Iraqi Al., R.A. (1986). Biological Activities of the Adult Beetle Epilachna chrysomelina Fabr. (Coleoptera: Coccinellidae). Iraqi Journal of Agricultural Sciences, 4: $1,69-77 ; 5$.

[2] Ali, M.A., \& El Saeady, A.A. (1986). Studies on Food Consumption and host selection of the melon ladybird beetle Epilachna chrysomelina F. (Coleoptera: Coccinellidae). Agricultural Research Review,61: 1,149-164; 14.

[3] Ali M.A., \& El Saeady A. A. (1982.) Factors Influencing Hibernation, Survival Rate and Reactivation of the Melon Ladybird Epilachna chrysomelina (F.) (Coleoptera: Coccinellidae).Acta Phytopathologica Academiae Scientiarum Hungaricae, 17:1-2, 157-162; 4 fig.; 9 ref.

[4] Anonymous, (1992). CAB International Institute of Entomology Distribution Maps of Pests. No. $57,82,182,296,409,529,530,531,532$.

[5] Camberos, U.N., Graziano J.V., \& Mojica, H.B. (1987). Prediccion del desarollo de Epilachna varivestis Mulstant. (Coleoptera; Coccinellidae) mediante unidales calor y relacion fenologica entre la plaga y el cultivo del frijol. Centro de Entomologia y Acarologia.Sobretiro Agrociencia Num.67, Chapingo, Mexico.

[6] Chen, L.F., Lu, Z.Q. \& Zhu, S.D. (1989). Biology of Henosepilachna vigintioctopuntata (Fabricius) and its effective accumulated temperature.Plant-Protection,No.1, 7-8.

[7] El-Abdin, A.M.Z., \& Siragelnour, B.G. (1991). Biological aspects, food preference and chemical control of the cucurbit beetle, Henosepilachna elaterii (Rossi) (Coleoptera; Coccinellidae). Arab Journal of Plant Protection, 9: 2, 103-110; 15 ref.

[8] El-Khidir, E.A., (1969). Contrubution to the biology of Epilachna chrysomelina F.,the melon lady beetle in the Sudan (Col.,Coccinellidae). Sudan Agric. Journal. 4:32-37.

[9] Giray, H. (1971). Epilachna chrysomelina F. (Coleoptera:Coccinellidae)'nin tanınmas1 ve biyolojisi üzerinde araştırmalar, Ege Üniversitesi Ziraat Fakültesi yayınları:186, Ege Üniversitesi Matbaası, İzmir, 57 s.

[10] Hodek, I., \& Honék, A. (1996). Ecology of Coccinellidae, Kluwer Academic Publisher Series Entomologica, vol.54, London, $464 \mathrm{p}$

[11] Izadpanah, K. (1989). Transmission of the Iranian isolate of the squash mosaic virus. IranianJournal-of-Plant-Pathology,25: 1-4, 3-5 (en), 11-15 (Pe); 12

[12] Katakura, H., Nakano, S., Kahono, S., Abbas, I., \& Nakamura, K. (2001). Epilachnine Ladybird Beetles (Coleoptera; Coccinellidae) of Sumatra and Java. Tropics, vol.10:(3), 325-352.

[13] Klemm, M. (1930). Beitrag zur Morphologie und biologie der Epilachna chrysomelina F. Zeitschr. Wiss. Insekt-Biol. 24(9-10): 231-251

[14] Melamed, V. (1956). Contribution to the biology on Epilachna chrysomelina in Israel. Rec. Agr. Res. St. Rehevot. Israel, 7: 83-95. 
[15] Mineo, G., Sciortino, A., \& Fazzari, A. (1994). Phytophages of winter melon in Sicily and economic damage by Aphis gossypii Glov. (Hom. Aphididae). Informatore-Fitopatologico, 44: (3), 58-63.

[16] Naim, A. (1971). The fauna of Iranian Coccinellidae. Entomologie et Phytopathologie Appliquees, No. 31, 11-14; pe 37; 3

[17] Nakano S. \& Katakura, H. (1999). Morphology and biology of phytophaggous ladybird beetle, Epilachna pusillanima (Coleoptera; Coccinellidae) newly recorded on Ishigaki Island the Ryukyus. Appl.Entomol. Zool.34 (1):189-194.

[18] Nazarov, D.T. (1988). Tests with preparations. Zashchita Rastenii Moskva., No.11, 31.

[19] Okuda, T., Gomi, T., \& Hodek, I. (1997). Effect of temperature on pupal pigmentation and size of the elytral spots in Coccinella septempunctata (Coleoptera: Coccinellidae) from four latitudes in Japan. Applied Entomology and Zoology.32:(4),567-572:8

[20] Perret, J. (1938). Observations complementaires sur la biologie d'Epilachna chrysomelina Fab. Au Maroc (coccinelle du melon). Rev. Path. Veg. 25 fasc., Paris, 74-80.

[21] Sağlam, Ö. (2003). Karpuz Telliböceği Henosepilachna elaterii Rossi. (Coleoptera: Coccinellidae)' nin farklı sıcaklık ve farklı konukçularda bazı biyolojik özellikleri üzerine araştırmalar. Trakya Üniversitesi Fen Bilimleri Enstitüsü Yüksek Lisans Tezi, 44 s.

[22] Tilavov, T.T. (1980). The daily and seasonal locomotory activity of the melon ladybird (Epilachna chrysomelina F.). Uzbekskii Biologicheskii Zhurnal, no. 5, 52-54; 4 fig.; 6

[23] Tilavov, T.T. (1981). The daily and seasonal feeding rhythm of the adult of the cucumber beetle (Epilachna chrysomelina F.), Uzbekskii Biologicheskii Zhurnal,No. 2, 49-51; 1

[24] Toguebaye, B.S., B. Marchand., (1984). Histological and cytopathological study of a naturally occurring microsporidiosis in the African curcurbit coccinellid, Henosepilachna elaterii (Col.: Coccinellidae), Entomophaga, 29: (4), 421-429

[25] Tripathi, S.R., \& Misra, A. (1991). Effect of temperature on development of Epilachna dodecastigma (Wied) (Coleoptera: Coccinellidae),Journal of Advanced Zoology, 12: 1, 45-49

[26] Uygun, N. (1981). Türkiye Coccinellidae (Coleoptera) Faunası Üzerinde Taksonomik Araştırmalar. Ç.Ü. Ziraat Fakültesi Yayın No:157, Bilimsel Araştırma ve İncelemeler, Tez no: $48,110 \mathrm{~s}$ 